\section{Value of Case-Based Learning within STEM Courses: Is It the Method or Is It the Student?}

\author{
Ashley Rhodes, ${ }^{\dagger *}$ Abigail Wilson, ${ }^{\dagger}$ and Timothy Rozell ${ }^{\ddagger}$ \\ ${ }^{\dagger}$ Division of Biology and `Department of Animal Sciences and Industry, Kansas State University, \\ Manhattan, KS 66506
}

\begin{abstract}
Undergraduate attrition from science, technology, engineering, and mathematics is well documented and generally intensifies during intermediate years of college. Many contributing factors exist; however, a mismatch between timing of certain pedagogical approaches, such as case-based learning, and the level of students' cognitive abilities plays a crucial role. Using cognitive load theory as a foundation, we examined relationships between case-based learning versus a traditional lecture and learning gains of undergraduates within an intermediate physiology course. We hypothesized instruction via a case study would provide greater learning benefits over a traditional lecture, with gains possibly tempered by student characteristics like academic preparation, as measured by ACT scores, and academic age, as measured by credit hours completed. Results were surprising. Casebased learning did not guarantee improved learning gains compared with a traditional lecture for all equally. Students with lower ACT scores or fewer credit hours completed had lower learning gains with a case study compared with a traditional lecture. As suggested by cognitive load theory, the amount of extraneous load potentially presented by case-based learning might overwhelm the cognitive abilities of inexperienced students.
\end{abstract}

\section{INTRODUCTION}

Increasing the number of students completing a postsecondary degree within the science, technology, engineering, and mathematics (STEM) fields is crucial for building and maintaining a strong workforce, yet loss of students from these fields during their undergraduate years continues to be problematic (President's Council of Advisors on Science and Technology, 2012; Graham et al., 2013; Freeman et al., 2014; Vilorio, 2014; Chen, 2015). Attrition from STEM fields may be caused by a number of complex factors that challenge both educators and students alike. For example, attrition has been linked to large classroom sizes; rapid pace of information delivery; a competitive atmosphere; uninspiring pedagogy that is seemingly irrelevant to the lives of students, causing a loss of interest; inability to see presented information as a cohesive whole; or simply feeling that they do not belong in STEM (Jozefowicz, 1994; Herreid et al., 2012; President's Council of Advisors on Science and Technology [PCAST], 2012; Graham et al., 2013; Freeman et al., 2014; Scott et al., 2017; Fisher et al., 2019). However, it is also possible that a mismatch in the timing of pedagogical tools used and the individual learning needs of students could also cause attrition from STEM fields. For example, Wood (2009) suggested that superior [SIC] students will progress from introductory to upper-level courses during their undergraduate years regardless of the teaching method used. However, students considered to be less academically oriented or self-motivated who leave STEM fields early in their college careers might do so because the curricular methods used are often seen as nothing more than a large collection of disconnected facts that rarely have much relevance to their daily lives and will soon be forgotten (Wood, 2009). Wood (2009) concluded that, for this group of
John Coley, Monitoring Editor

Submitted Oct 18, 2019; Revised Jun 8, 2020; Accepted Jun 23, 2020

CBE Life Sci Educ September 1, 2020 19:ar44 DOI:10.1187/cbe.19-10-0200

*Address correspondence to: Ashley Rhodes (aek6613(aksu.edu).

(c) 2020 A. Rhodes et al. CBE-Life Sciences Education @ 2020 The American Society for Cell Biology. This article is distributed by The American Society for Cell Biology under license from the author(s). It is available to the public under an Attribution-Noncommercial-Share Alike 3.0 Unported Creative Commons License (http://creativecommons.org/licenses/ by-nc-sa/3.0).

"ASCB®" and "The American Society for Cell Biology $® "$ are registered trademarks of The American Society for Cell Biology. 
students, the issue lies not in what we teach but in how we teach. This conclusion is both encouraging and yet perhaps a little puzzling for educators, many of whom go to great lengths to help all students within their courses succeed. While some suggestions for helping to alleviate the dissonance between academic preparation and success within STEM courses have been made, they sometimes appear ambiguous or perhaps too complex for educators to tackle. For example, improving student preparation during junior high and high school could translate to better success in college (Ejiwale, 2013). Additionally, improving STEM instructor preparation at multiple levels could be helpful (Goldhaber and Brewer, 1998; Ingersoll and Perda, 2010; PCAST, 2012). Also, adding more engaging activities within STEM courses could be beneficial for helping underprepared students see connections between in-class learning and real-life applications (Villanueva and Hand, 2011; Kennedy and Odell, 2014).

In contrast to some of these more open-ended suggestions, one solution that has been promoted for increasing student success in STEM is the use of active-learning approaches such as case-based learning (Lundeberg, 2008; Kaddoura, 2011; McRae, 2012; Herreid and Schiller, 2013; Greenwald and Quitadamo, 2014; Stains et al., 2018). Case-based learning encourages students to use techniques that help them integrate, synthesize, and apply newly learned information to a broader context, both to help them see the value of what they are learning and to foster critical-thinking skills (Jozefowicz, 1994; Graham et al., 2013; Greenwald and Quitadamo, 2014).

Case-based learning can take many forms but generally relies upon the use of a case study that describes a specific situation or clinical case and requires students to work through the information to generate solutions and solve problems (Herreid, 2006; Wood, 2009; Popil, 2011; Savery, 2015; McLean, 2016). Case studies can vary substantially in length, format, delivery, and the type of media included. Cases may emphasize problem solving, debates, flexible thinking, development of alternative strategies, and even the use of skepticism (Herreid, 2004). Implementing cases within courses can also vary, but according to Herreid (1998), four major classifications exist in regard to what students do: participate in small-group activities, participate in discussions, listen to a lecture, or work alone completing an individual assignment. Thus, when or how a case study is delivered to students, the responsibilities of students, interactions between students, and even case study assignments that entail students working individually or in groups all vary (Popil, 2011; Thistlethwaite et al., 2012).

Comparing case-based learning to more traditional forms of learning has resulted in reports of increased learning gains (Kaddoura, 2011; Bonney, 2015), decreased learning gains (Andrews et al., 2011; Thistlethwaite et al., 2012), and no significant changes (Dochy et al., 2003; Halstead and Billings, 2005; Hoag et al., 2005; Terry, 2007; Kulak and Newton, 2014). Some researchers have also reported that case-based learning is effective, but only if supported by supplementary didactic lectures that structured student understanding of the material (Cliff, 2006; Baeten et al., 2013), or that case-based learning improved student attitudes but not always student learning (Wilke, 2003). This disparity could be caused by several factors. For example, it is not currently known how much background knowledge or preparation students should have before they can effectively engage with case-based activities (McLean, 2016), when and how instructors should deliver these activities (Lundeberg, 2008), and how much instructor guidance is required (McRae, 2012).

It is possible that the existing uncertainty regarding who exactly benefits from case-based learning in comparison to other teaching methods could be due to the number of studies primarily relying upon survey data to make conclusions as to the value of this approach (Cliff and Wright, 1996; Knight et al., 2008; McLean, 2016; Kaur et al., 2019) and the number of studies that did not use a control and thus lacked a true experimental design (Greenwald, and Quitadamo, 2014; Kulak and Newton, 2014). Furthermore, few authors have specifically investigated the utility and potential benefits of case-based learning in regard to certain undergraduate student characteristics or provided clear guidance regarding when and how to use case-based learning within undergraduate courses (Lundeberg, 2008; Kulak and Newton, 2014; McLean, 2016). Thus, we believe our overarching research question is important when using case-based learning within undergraduate STEM courses: For whom is it useful?

\section{Theoretical Framework}

Cognitive load theory (CLT) serves as the foundation for this research, as it provides guidance for investigating relationships between instructional design and student learning gains (Paas et al., 2003a). According to CLT, cognitive processes, and thus learning, are impacted by three types of cognitive loads: extraneous load, intrinsic load, and germane load. These loads are additive and must be appropriately managed for optimal learning, but how they are managed differs based on student characteristics such as previous academic experiences, prior knowledge, and learning preferences. For example, extraneous loads, defined as superfluous information that does not directly relate to learning objectives, should be minimized wherever possible. This is especially true for novice learners, whose ability to take in new information can quickly be overloaded, even when completing common tasks such as searching for and applying information to solve a problem (Paas et al., 2003a). In contrast, intrinsic loads, defined as the degree of difficulty inherent to a discipline, can be more difficult for instructors to manage. Intrinsic load must be supported by appropriately scaffolding information, but should never be minimized, as simplification could give an artificial impression of the discipline and potentially erode the ability to critically think about the information in future contexts (Paas et al., 2003a). However, the degree of scaffolding required is unique for each learner; thus, designing a curriculum or even an individual activity that appropriately manages intrinsic load becomes difficult, especially in large courses with diverse enrollment. According to Paas et al. (2003a), the key to successfully managing intrinsic load is to consider element interactivity, or the number of interacting items, that must be simultaneously managed to understand a concept. If this number is high, which is often the case within STEM courses, then additional instructional support is often required; for novices, the recommendation is to omit all but the most essential interacting elements. Germane loads, defined as the amount of effort a learner is willing to expend to understand a concept, can be positively impacted by instructional design, but only if the needs of the learner are matched and 
supported by the way in which information is presented. For example, learners who have little background in a subject, and thus underdeveloped abilities to synthesize and use new information, benefit from instructional tools that present information directly and do not require searching for or synthesis of abstract ideas, while the opposite is true for learners who have prior and positive experiences with the subject (Paas et al., 2003a,b; Sweller et al., 2011; Young et al., 2014).

\section{Conceptual Framework}

Using CLT as a theoretical framework, we explored potential relationships between comprehension of complex information that had a high intrinsic load, the experience of learners based upon individual characteristics such as level of academic preparation, and two distinct instructional formats that varied in amount of extrinsic load yet contained the same content. One instructional format included the use of an interactive case study that was designed to engage students with a story and scaffold their nascent understanding of the information presented by chunking information into manageable sections, each one containing explanatory text, interactive graphics, and critical-thinking questions. While carefully designed and aligned with suggestions on case study development, this format did carry a higher extrinsic load due to the number of interacting elements that had to be considered in order to understand the information.

The second instructional format represented a more traditional teaching method and included a didactic lecture using bulleted PowerPoint slides that also included the same graphics presented within the case study; however, the lecture format was devoid of interactive activities and questions and involved only a lecture during which students mostly listened but were allowed to ask questions at any time. This format had a lower extrinsic load due to the decreased number of interacting elements that needed to be considered at any given time to understand the information.

These two instructional formats were used within a large, intermediate-level undergraduate physiology course with a diverse student body that varied in age and academic preparation. However, all were majoring in a STEM discipline, and many aspired to matriculate into a professional school upon graduation. Thus, while variation did exist within the population, we believe it is an accurate portrayal of the natural variation found within most large STEM courses at this level.

\section{METHODS}

To examine the utility of case-based learning and the benefits it may provide in regard to specific student characteristics in comparison to a more conventional format of learning, we investigated the following two research questions:

1. Compared with a conventional learning format such as a traditional lecture, how do student learning gains differ when using a case study?

2. How do student characteristics such as general academic preparation and credit hours completed relate to learning gains derived from the use a case study?

\section{Setting and Participants}

This study took place at a large, midwestern, land-grant university with an admissions acceptance rate of $94 \%$. Participants were recruited from an intermediate (300 level at a university in which undergraduate courses start at 100 and go through 600) physiology course offered within a biology department. During the semester in which the study was conducted, the course was open to all students who had completed introductory biology and chemistry courses and received a " $\mathrm{B}$ " or better in both. Furthermore, this course was an 8 credit-hour course that included several components such as lecture, laboratory, and cadaver dissection; thus, most students were very committed to learning, as their grades would have had a significant impact on their overall grade point averages. Applications of course material on exams and quizzes tended to be focused on human health and applications to allied health professions. The average ACT score of students was 26.6. Of the 134 students enrolled, all chose to participate, although only 122 completed all portions of the study due to absences. The final distribution of students completing all components of the study represented a mixture of 34 sophomores, 59 juniors, and 29 seniors. Information related to gender and ethnicity was not tracked.

Participation in the study was voluntary, and all activities were approved by our Institutional Review Board (IRB protocol no. 7028). Students were awarded a small amount of extra credit for participating. Students were provided the option of an alternative assignment if they did not want to participate; however, none selected this option.

\section{Development of Case Study and Conventional Lecture Treatments}

Both the case study and conventional lecture were created by the authors to specifically deliver information about insulin resistance and its progression to type II diabetes. Not only do these topics encompass suggestions by Michael et al. (2017) about pertinent concepts that should be taught within undergraduate physiology courses, such as flow-down gradients between blood and interstitial fluid and details of cell membranes, but they also align well with suggestions made by Allen et al. (1996) regarding topic selection for the design of critical-thinking activities. The case study was created using a design-based research process that entailed four iterations. Each iteration was reviewed by graduate teaching assistants as well as three STEM instructors. After each iteration, feedback was used to revise and improve the case study. The final iteration of the case study authored by Wilson et al. (2017) was peer reviewed and published by the National Center for Case Study Teaching in Science.

The case study included a short story about an individual who, through diet and lack of exercise, proceeded through the stages of insulin resistance and pre-diabetes and eventually developed type II diabetes. Immediately following each section about this individual's story, accompanying informational text as well as interactive figures and graphics describing the physiology of what was occurring were presented. The story, text, and graphics were presented in small sections, a strategy known as chunking, which is encouraged when presenting complex information that has multiple interacting elements (Mayer and Moreno, 2003). The interactive figures and graphics, which displayed the same information presented within the text, required students to apply what they had just read to complete them as described by carefully written instructions. And finally, critical-thinking questions were placed at the end 


\section{Story Cont'd:}

After Timmy plays a hard game of basketball, he likes to cool down with a large chocolate milkshake. Every time he gulps down his post-workout milkshake he notices that he's ready for more basketball action, almost as though he has a renewed level of energy. His muscles feel good and he's ready for more. Considering Timmy's burst of energy after his ice cream ritual, we can conclude that he is able to absorb and use glucose efficiently for energy production within his skeletal muscle cells which provides him with the ability to run, dribble, and shoot a basketball.

\section{Mechanism of Glucose Absorption in Small Intestine:}

Once carbohydrates like glucose are broken down into their monomers, the process of absorption can begin. The sodium glucose-linked transporter (SGLT-1) is the primary transporter used for glucose absorption from the lumen of the small intestine into the intestinal epithelial cells called enterocytes. As indicated by its name, the SGLT-1 moves both sodium and glucose at the same time making it a symporter. Like most symporters, the SGLT- 1 relies on the work of Na+/K+ pumps to keep intracellular sodium levels low. These pumps are located along the membranes, especially basolateral membranes, of enterocytes and use ATP to continuously pump sodium out of the cell while pumping $\mathrm{K}+\mathrm{in}$. Once glucose enters the enterocyte via the SGLT-1 it will diffuse into the extracellular fluid (ECF) through a protein called GLUT2, which is also located on the basolateral membrane. GLUT2 permits facilitated diffusion, as glucose moves from a high concentration to a low concentration.

When luminal glucose levels are high, for example, after finishing a meal, GLUT2 can also assist the SGLT-1 transporters on the apical side of the enterocytes. The translocation, or movement between cellular compartments, of some GLUT2 transporters from the basolateral membrane to the apical membrane of the enterocyte helps increase glucose absorption.

Guided Practice - Glucose Absorption in the Jejunum of the Small Intestine:

Instructions - Apply information about mechanism of glucose absorption and complete graphic below by:

- Label the Na+/K+ pumps, SGLT-1 transporters, GLUT2 transporters.

- Then, indicate the direction in which glucose and sodium are moving through the SGLT-1 and GLUT2 transporters using arrows. Assume glucose levels in the small intestine (lumen) are very high.

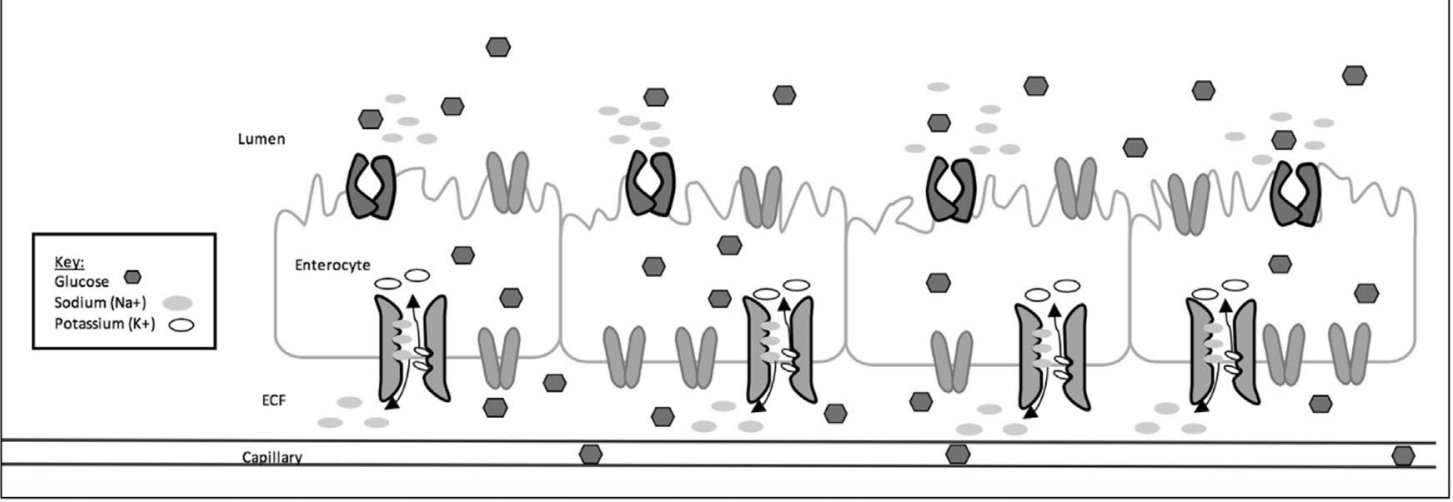

FIGURE 1. Typical features of the case study design. This particular portion was taken midway through the case study after students had been presented with information about the basics of carbohydrate breakdown in the digestive system. Specific features related to chunking and scaffolding include a short story, a small amount of explanatory text, and instructions explaining how to interact with a graphical feature designed to help students visualize the information. Additionally, the explanatory text and visuals were placed very close to each other, and vocabulary used in the explanatory text matched vocabulary used in the visual in order to reduce cognitive load.

of each section or chunk, and students were asked to think about what they had just learned before moving to the next section. Figure 1 provides a sample of the case study design features.

Students in the lecture treatment, which consisted of a traditional lecture with PowerPoint slides and accompanying handouts of the slides, received the same physiological information presented in the case study. For example, the lecture and handouts included static versions of the figures and graphics found in the case study, and these were described directly to students by the instructor. This presentation was also subjected to four iterations of review and improvement by graduate students and other STEM instructors. Thus, the major differences between the case study and conventional lecture treatment groups were that students in the latter group were not presented with a story or required to complete activities associated with the graphics. In short, the conventional lecture contained little to no extraneous information.

\section{Implementation of Treatments}

Both treatments were administered during regularly scheduled lab periods within a single week of the semester and before any presentation of glucose homeostasis by the primary instructor in either lecture or lab. At the beginning of each treatment, the same instructor provided a brief overview of the activities and goals. For the case study group, this also included instructions on how to work through the case and specifically how to interact with the graphics. This instructor was the lead author of the case study and conventional lecture treatment and was also a lab instructor for the course; thus, comfort level with techniques, delivery, students, and content was high.

Students in both treatments were instructed to work alone, as one of our main objectives was to correlate student characteristics such as academic preparation and experience with learning gains when extrinsic load was varied between treatments. Thus, we purposefully did not allow students to work in groups, as this would have made our data difficult to interpret 


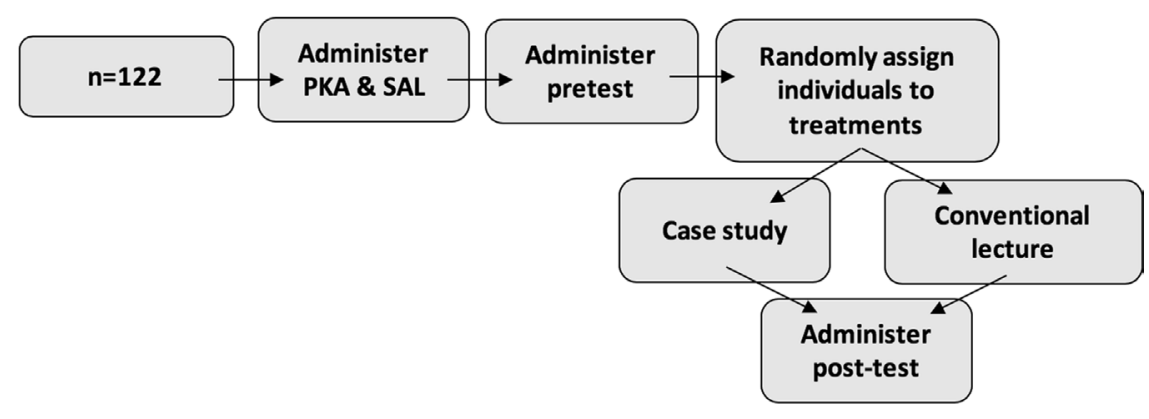

FIGURE 2. Experimental design. Students completed the PKA and SAL survey on the first day of class, then a topic-specific pretest was given a week before randomizing participants into either the case study or conventional lecture treatment. A posttest, which was identical to the pretest, was given immediately after each treatment. Not shown in this graphic is the collection of ACT scores, which occurred at the end of the semester after final grades had been submitted.

in regard to individual student gains. However, students in both treatments were told several times they could ask the instructor questions at any time while working through the case study or listening to the lecture.

\section{Experimental Design}

Using the pretest/posttest comparison group design (Campbell and Stanley, 1963), we assessed differences in student learning gains resulting from the use of a case study versus a conventional lecture over the same concepts. Participants were recruited using a convenience sampling method, with 122 completing all components of the study, which included a prior knowledge assessment (PKA; Rhodes and Rozell, 2017), a modified version of the Student Approach to Learning (SAL) survey (Marsh et al., 2006; Rhodes and Rozell, 2017), a pretest, a learning treatment, and a posttest. Experimental design components and schedule are described in Figure 2.

\section{PKA}

The PKA was used to assess the background knowledge of students about core physiological concepts and was administered on the first day of class. The PKA (Appendix A in the Supplemental Material) consisted of 10 multiple-choice questions, with each question potentially having multiple correct answers. To receive the full point(s) for each question, students had to have selected all the correct answers and none of the incorrect answers on this assessment. This grading procedure was used to reduce awarding points for guessing. Students received 1 extra credit point for completing the PKA that was not dependent on the score. The PKA was created and refined over a period of several years within this specific course before being used in this study.

\section{SAL Survey}

For evaluating how students approach learning new information presented to them in a formal course setting, a modified version of the SAL survey was used (Appendix B in the Supplemental Material). This survey was designed to assesses a variety of student characteristics, such as self-regulated learning strategies, motivation, confidence, and learning preferences (Marsh et al., 2006). For this study, we only selected questions from the SAL that evaluated the self-regulated learning strategies of students, specifically memorization and elaboration, and generated an individual SAL metric for each student, as previously described by Rhodes and Rozell (2017). This metric could then be used to quantify and compare results from the SAL with other components of the study.

\section{Pretest and Posttest}

Both the pretest and posttest (Appendix C in the Supplemental Material) consisted of 10 multiple-choice questions that could have multiple correct answers. Full points for each question were awarded only if every correct answer had to be selected and none of the incorrect answers selected. As with the PKA, this all-or-nothing grading scheme was used to reduce the chance of receiving full credit due to guessing.

To ensure that questions asked on the posttest were appropriate and understandable for students after receiving either treatment, we applied an item difficulty index (IDI) before analyzing statistical results related to the research questions. As discussed by Tavakol and Dennick (2011), this metric can be used to determine whether a question effectively measured comprehension by students after receiving a particular form of instruction. The following formula was used to calculate the IDI, where $R$ is the number of students who answered the question correctly; $N$ is the number of total responses, including those that were correct, incorrect, or left blank; and $i$ refers to the question number:

$P_{i}=R_{i} / N$

While the IDI can range from 0 to 1 , with very difficult questions having a score nearing 0 and very easy questions have a score approaching 1 , the IDI of each question should have ideally ranged between 0.3 and 0.8 (Tavakol and Dennick, 2011). The IDI for question 10 on the posttest was outside the ideal range, possibly due to the complexity of the question. Statistical analyses were performed both with and without question 10, but results did not change. Results of the IDI are shown in Table 1.

\section{The ACT College Readiness Assessment}

The ACT is a standardized college entrance exam that assesses college readiness and is often a prerequisite when applying to colleges. After gaining permission from student participants and our IRB, ACT scores were collected from the university's online information system after the semester was over.

TABLE 1. Results of the Item Difficulty Index.

\begin{tabular}{lcccccccccc}
\hline & Q1 & Q2 & Q3 & Q4 & Q5 & Q6 & Q7 & Q8 & Q9 & Q10 \\
\hline Case study & 0.6 & 0.48 & 0.40 & 0.53 & 0.65 & 0.68 & 0.68 & 0.42 & 0.61 & 0.06 \\
Lecture & 0.75 & 0.32 & 0.30 & 0.55 & 0.65 & 0.57 & 0.77 & 0.55 & 0.47 & 0.07 \\
\hline
\end{tabular}




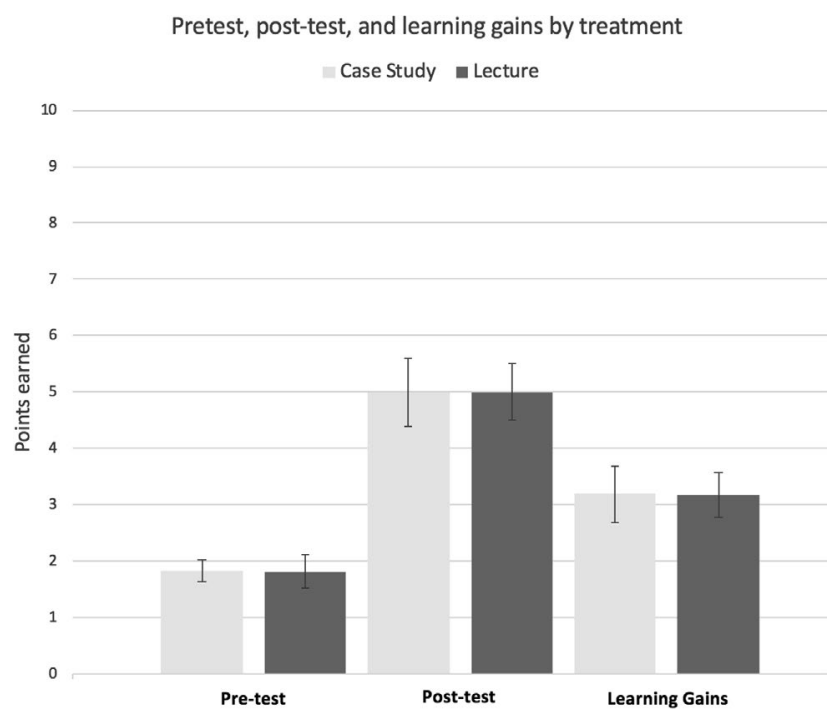

FIGURE 3. Results of pretest, posttest, and learning gains by treatment. Values on the $y$-axis are points earned on the identical pretest and posttest assessments, with potential scores ranging from 0 to 10 . Both pretests and posttests were graded "all or none" to avoid guessing. For each student, the pretest score was subtracted from the posttest score to calculate learning gains. Bars shown are means plus or minus SD. No statistical differences were found between means for any of the parameters tested $(p \geq 0.05)$.

\section{Credit Hours Completed}

The number of total credit hours completed at the start of the study was collected and used as a metric of academic age or experience. After gaining permission from student participants and our IRB, information was retrieved via the online university information system.

\section{Statistical Analyses}

All data were analyzed using IBM's SPSS v. 26. Differences between means were evaluated using one-way analysis of variance (ANOVA). Correlations between variables for student data were calculated using Spearman's rank-order correlation test. This test was selected as it is slightly more conservative than Pearson's, our data were monotonic, and we included more than one outlier for each correlation performed. Statistical significance was defined as $p \leq 0.05$.

\section{RESULTS}

Our analyses yielded several noteworthy and unexpected results. In regard to our first research question, "Compared with a conventional learning format such as a traditional lecture, how do student learning gains differ when using a case study?," we found no differences by treatment (Figure 3). Using a oneway ANOVA, we found that the means of posttest scores for students in the case study group were not statistically different from students in the conventional lecture group, $F(1,119)=$ $0.025, p=0.874$. Furthermore, learning gains of students in the case study group were not statistically different from those of students in the conventional lecture group, $F(1,119)=0.027$, $p=0.946$.

For further verification, learning gains by treatments were also analyzed using the average normalized gain equation for estimating the impacts of case-based learning as developed by Hake (1998a,b), where (Post - Pre)/(10 - Pre). Normalized learning gain was 0.40 for the case study treatment and 0.39 for the conventional lecture group, corroborating that no statistical differences existed in learning gains by treatments.

In regard to our second research question, "How do student characteristics such as general academic preparation and credit hours completed relate to learning gains derived from the use of a case study?," we found that the benefit of case-based learning was correlated with certain student characteristics. The use of a case study did not automatically translate to higher learning gains for all. Instead, it appears as though certain student characteristics predicted learning gains when case-based learning was used but this was not true when traditional didactic lectures were used. For example, as displayed in Figures 4A through 7A, positive and significant correlations existed between learning gains from the use of a case study and prior knowledge levels, $r(59)=0.275, p=0.034$; preferences for
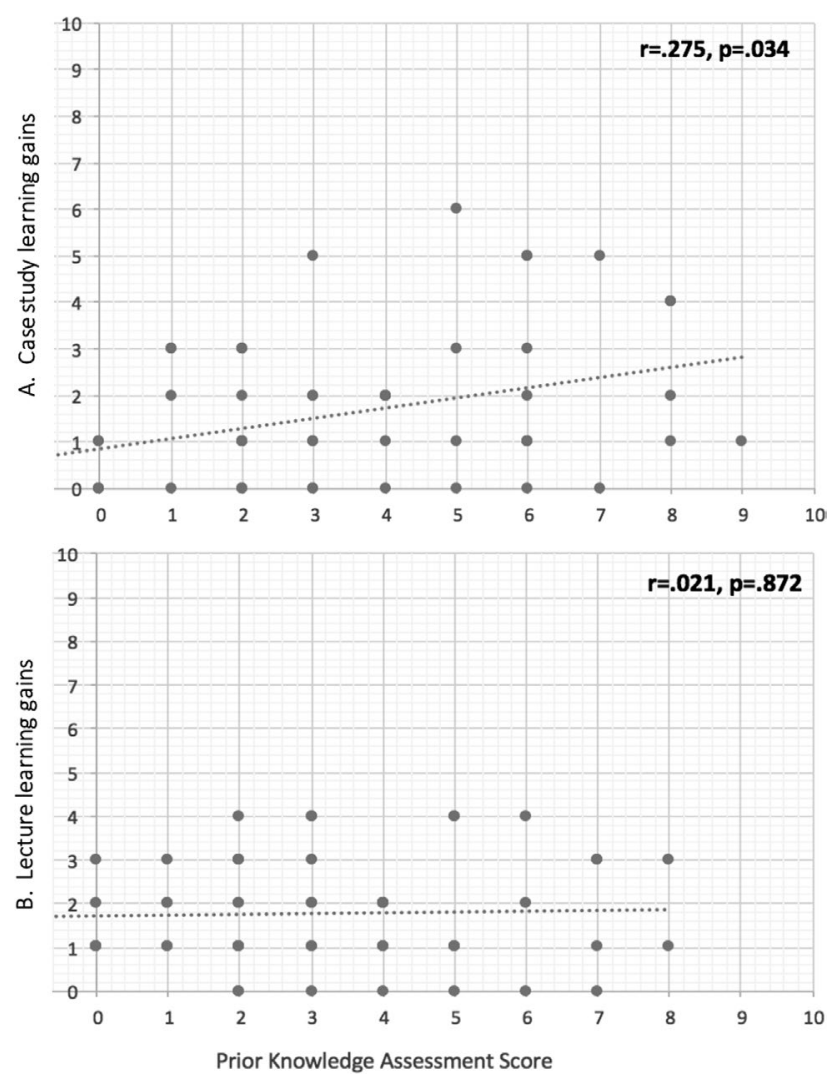

FIGURE 4. Effect of prior knowledge on learning gains. Participants were given a prior knowledge quiz that consisted of 10 multiple-choice questions with multiple potential correct answers, graded all or none. Identical pretest and posttest quizzes over the specific topics covered by the case study (A) or lecture (B) treatments consisted of 10 multiple-choice questions with multiple potential correct answers, graded all or none. Learning gains were calculated by subtracting pretest score from posttest score for each participant. A Spearman's rank-order correlation test was used to determine relationships between prior physiology knowledge and learning gains, and correlations were considered to be significant at $p \leq 0.05$. 

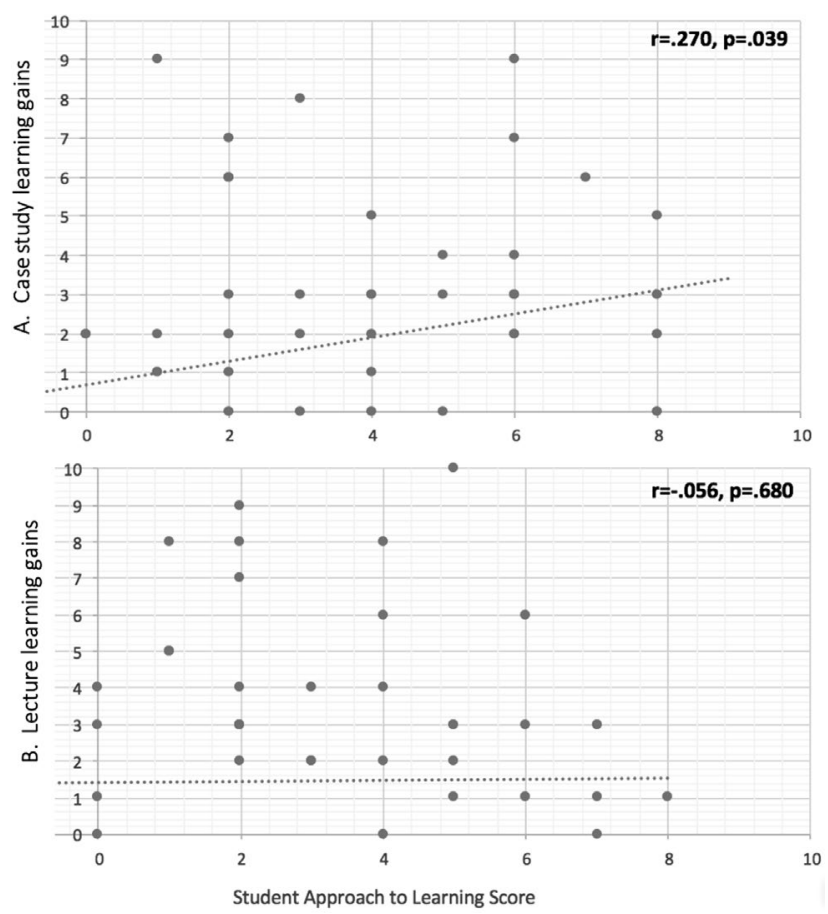

FIGURE 5. Effect of participant's approach to learning on learning gains. Participants were given a survey (the SAL) that assessed their preferred approach to learning on a five-point Likert scale, and a calculated SAL metric was used to quantify whether the preferred approach was memorization (SAL metric scores) or elaboration (higher SAL metric scores). Identical pretests and posttests over the specific topics covered by the case study (A) or lecture (B) treatments consisted of 10 multiple-choice questions with multiple potential correct answers, graded all or none. Learning gains were calculated by subtracting pretest score from posttest score for each participant. A Spearman's rank-order correlation test was used to determine relationships between SAL metric scores and learning gains, and correlations were considered to be significant at $p \leq 0.05$.

elaboration over memorization as measured by the SAL metric, $r(59)=0.270, p=0.039$; ACT scores, $r(53)=0.479, p=0.000$; and college credit hours completed, $r(61)=0.299, p=0.019$. However, as shown in Figures 3B through 7B, no relationships existed between learning gains from the use of a traditional lecture and student characteristics such as prior knowledge levels, $r(60)=0.012$, $p=0.872$; preference for elaboration over memorization as measured by the SAL metric, $r(56)=-0.056$, $p=0.680$; or college credit hours completed, $r(60)=-0.024$, $p=0.855$. A positive and significant correlation did exist between ACT scores and learning gains from a traditional lecture, $r(52)=0.276, p=0.047$.

\section{CONCLUSION AND DISCUSSION}

The overarching purpose of this study was to investigate the relationship between the use of case-based learning within an intermediate-level undergraduate STEM course and correlate specific student characteristics such as academic preparation and experience with learning gains. We were specifically interested to see whether case-based learning represented a beneficial and equitable form of learning for all participants, or, as
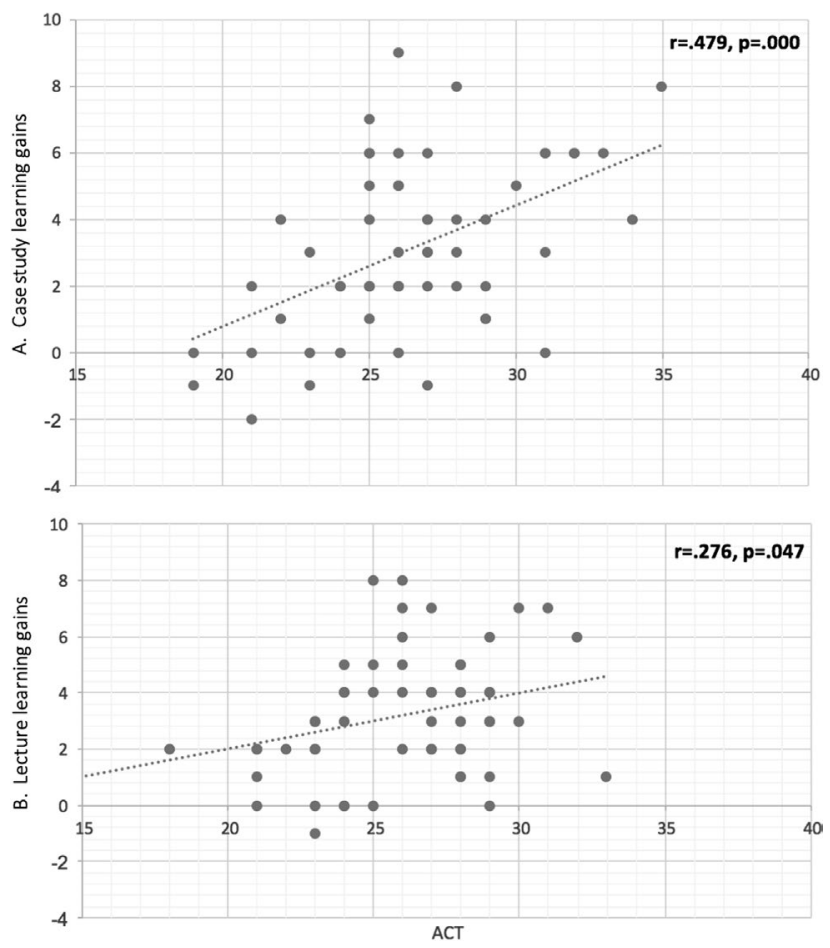

FIGURE 6. Effect of standardized test performance on learning gains. Scores from the ACT exam taken before college entrance were collected with permission of the participants. Identical pretest and posttest quizzes over the specific topics covered by the case study (A) or lecture (B) treatments consisted of 10 multiplechoice questions with multiple potential correct answers, graded all or none. Learning gains were calculated by subtracting pretest score from posttest score for each participant. A Spearman's rank-order correlation test was used to determine relationships between ACT scores and learning gains, and correlations were considered to be significant at $p \leq 0.05$.

predicted by CLT, whether some students perhaps benefited more from a traditional lecture due to its simpler structure and reduced cognitive load. We were also interested in providing realistic suggestions to other educators who may be considering the use of case-based learning in their courses in piecemeal manner to replace certain lectures or perhaps a laboratory activity but are unable to replace an entire semester's curriculum given the resources required (Colliver, 2000). As explained by Aikens and Dolan (2014) and Albanese (2000), replacing single lessons or activities is more realistic when trying something different in most courses. Also, given the findings of Stains et al. (2018), most STEM instructors naturally move between different teaching formats, even within a single teaching period. Thus, providing evidence-based guidance on when to use certain formats and with which population of students may help direct the timing and implementation of certain activities.

In regard to our first research question, "Compared with a conventional learning format such as a traditional lecture, how do student learning gains differ when using a case study?," we found no differences between treatments. Our findings were consistent with those of other authors such as Hoag et al. (2005), who found no difference in learning gains between the use of a case study compared with a didactic lecture for students 

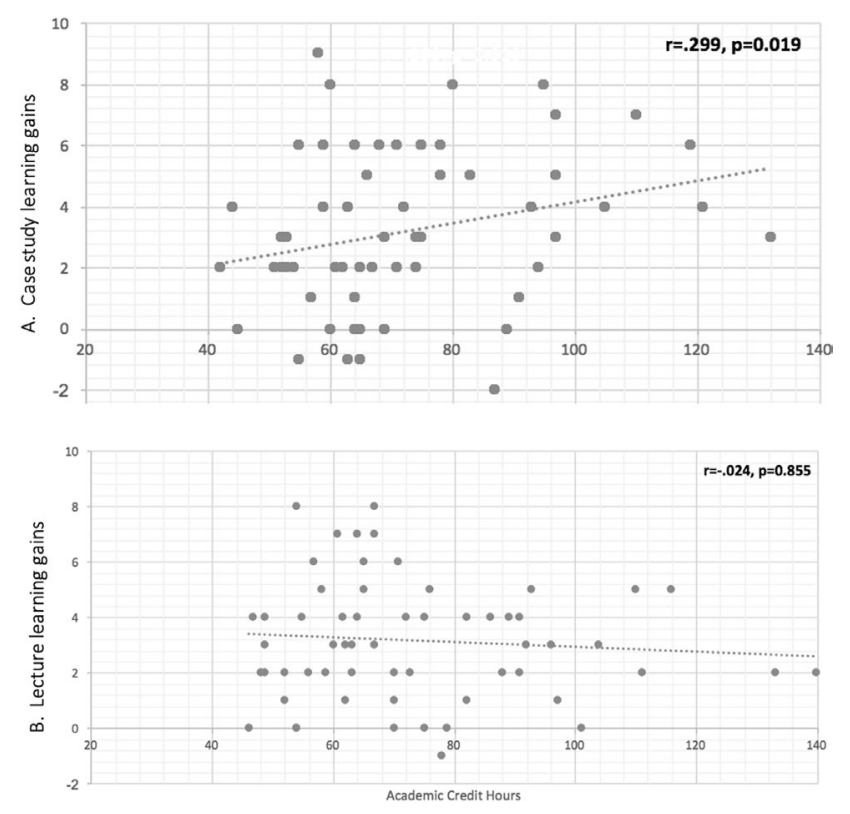

FIGURE 7. Effect of academic experience on learning gains. The number of credit hours completed was collected for participants with their permission. Identical pretest and posttest quizzes over the specific topics covered by the case study $(A)$ or lecture (B) treatments consisted of 10 multiple-choice questions with multiple potential correct answers, graded all or none. Learning gains were calculated by subtracting pretest score from posttest score for each participant. A Spearman's rank-order correlation test was used to determine relationships between college credits completed and learning gains, and correlations were considered to be significant at $p \leq 0.05$.

enrolled in an undergraduate immunology course when assessing critical-thinking skills via a multiple-choice test. Similarly, Terry (2007) assessed introductory biology students' critical-thinking skills using the Watson-Glaser Critical Thinking assessment and found no differences between students in a case-based learning group versus a traditional lecture group. Furthermore, in a study conducted by Baeten et al. (2013), which compared case-based learning with traditional lectures, it was found that case-based learning did not produce deeper learning unless supplemented with a well-structured didactic lecture first, so that students could understand the content discussed in the case study before attempting to complete it. This finding was similar to that described by Cliff (2006), who reported that, if case-based learning was used in an undergraduate STEM course, additional supplementation with well-structured material was often required to help students understand content. And finally, Dochy et al. (2003) conducted a meta-analysis comparing case-based learning to learning via traditional lectures in a clinical skills course for medical students and found that, while application of knowledge and higher-order thinking for professional students using case-based learning was higher immediately after the case-based learning experience, there were no differences between groups when given multiple-choice posttests measuring accumulated and retained knowledge at a later point.

For our second research question we asked, "How do student characteristics such as general academic preparation and credit hours completed relate to learning gains derived from the use of a case study?," and attempted to isolate case-based learning benefits by certain student characteristics. This question was not only driven by the lack of information specifically addressing who benefits from case-based learning within undergraduate STEM courses, but also by other authors such as Lundeberg (2008) and Yadav et al. (2007) who questioned how much background students should have to be successful when using case-based learning. We found that success with case-based learning is likely predicted by certain student characteristics, such as having a stronger academic background coming out of high school, as indicated by the correlations between ACT scores and learning gains, or having more college experience, as indicated by the correlations in our study between college credit hours completed and learning gains. Our results were consistent with other authors investigating similar questions with undergraduate students. For example, Halstead and Billings (2005) found that case-based learning may become frustrating for less-prepared students or those who are used to more traditional methods. Similarly, McRae (2012) stated that "case studies can cause confusion and cognitive frustration if students do not have the prerequisite knowledge to handle the information" (p. 1175).

Our results, as well as those reported by Halstead and Billings (2005) and McRae (2012), can perhaps be explained by CLT, which provides a framework for understanding the relationship between cognitive processes of learners and the structure of information (Paas et al., 2003a). According to this theory, when novice learners are attempting to comprehend complex information consisting of multiple interacting elements, especially for the first time, extraneous details should be minimized, as they can quickly overload novice learners' cognitive abilities. Although we did not directly test for this, it is likely that the story, explanatory text, and interactive graphics that were part of the case study presented too much extraneous detail for some students. It is also possible the interactive graphics themselves, which required a student to have a certain level of reading comprehension to extract pertinent information from the story and apply it correctly to a graphic, were too overwhelming. In comparison, the traditional learning format used in this study, which consisted of a basic PowerPoint presentation and didactic lecture, contained little to no extraneous information and required a much lower level of reading comprehension. Perhaps as a student gains more experience and his or her cognitive abilities evolve, the addition of extraneous details can be beneficial, as it makes the information more interesting and challenging and encourages the student to see how elements interact. This notion was also supported by Paas et al. (2003a), who suggested the addition of previously omitted details can foster a deeper level of understanding for more advanced learners, and is also reinforced by McParland et al. (2004), who found that older students were less likely to use surface learning approaches, such as memorization, and were thus more likely to be able to make meaning from complex activities.

Summarizing our findings in light of outcomes reported by other authors, we believe our results provide several novel additions to the field of case-based learning. First, the use of a case study by itself might not always yield increased learning gains 
compared with more traditional teaching methods, especially if students are asked to work through the case study individually. This is more likely to be true if students have less background and academic preparation or have less college experience in general. It is also more likely to be true if students rely upon memorization when learning new information and are unsure of how to assimilate information, as indicated by our correlations, which show relationships between student approach to learning and learning gains with a case study versus a lecture. In large-enrollment courses, where there is likely to be variation regarding student abilities, it is possible that a more traditional form of teaching such as a lecture, at least initially, might represent a more equitable form of learning. After the playing field has been leveled, so to speak, case-based learning may become more useful to more students. This is consistent with work by McLean (2016), who concluded that advance preparation of the student was necessary for case-based learning to be effective and after that cases could be a powerful stimulant for learning. Second, our study provides helpful insights into the benefits and drawbacks of using case-based learning with an often-overlooked population of students: intermediate-level undergraduates. Given that attrition rates from STEM often intensify during this time, especially for lower-performing students (Strenta et al., 1994; Seymour and Hewitt, 1997; Maltese and Tai, 2010; PCAST, 2012), having some information about which teaching tools to use or avoid at certain time points could be beneficial.

We would like to acknowledge that many studies supporting case-based learning have been reported with nursing students (Kaddoura, 2011; Popil, 2011), medical students (Wood, 2009; Nair et al., 2013; McLean, 2016; Kaur et al., 2019), graduate students (McRae, 2012), and even vetted upper-level undergraduates enrolled in a majors course (Cliff and Wright, 1996; Knight et al., 2008; Greenwald and Quitadamo, 2014). In fact, according to McLean (2016), medicine represented almost 73\% of published studies, followed by dentistry at $5 \%$, pharmacy at $5 \%$, and nursing at $3 \%$, while published studies detailing the use of case-based learning in mixed, undergraduate courses represented $1.4 \%$ of the articles published globally (p. 41). Clearly, fewer researchers have examined when and how to use case-based learning with intermediate-level undergraduates, leaving many questions for educators who teach at this level.

As with any study, this one was not without limitations. For example, we specifically wanted to examine relationships between individual students and case-based learning versus a more traditional form of learning, and to do this, we had students work by themselves in both treatments. Typically, casebased learning is done with students working in groups. However, group work can often mask the performance of lower-achieving students, as a small minority of students can dominate group work (Lundeberg, 2008). This idea was also supported by McRae (2012), who reported that, when students worked in groups as part of case-based learning, lower-performing students often rode the coattails of better-performing students and may have learned less than they appeared to learn. Additionally, it is possible that students with lower reading comprehension gained less when learning with a case study compared with a traditional lecture. We did not collect or assess reading comprehension scores, but it would be something to consider for the future, given the typical reliance upon reading skills when learning from a case study. Furthermore, empirically assessing the value of different types of activities within a case study, such as multimedia or other interactive features that help students scaffold their nascent understanding of the information provided by the case study, would be a helpful addition to the literature. It is very possible that case studies could become a powerful tool to help engage underprepared students if the right supportive features were included. And finally, we would like to acknowledge that learning gains in both treatments used in this study were lower than we had hoped and perhaps indicate that the concepts presented were too difficult for students at this level, and this could have impacted our results.

In conclusion, while case-based learning increased learning gains for some students, it is possible that these gains may not be equally achievable by all students within large undergraduate courses due to the diversity of student characteristics. The advantages of case-based learning are likely more tangible for students who have stronger academic backgrounds and are better equipped to assimilate information from multiple sources when learning new concepts as opposed to relying upon memorization and for those with more college experience. In large, diverse, undergraduate courses, we believe it is important to provide a more equitable form of learning for all students, and in these instances, we suggest supporting case-based learning activities with other pedagogical tools, including didactic lectures. It is possible that the provision of complex information, made upfront or ahead of time in a more simplified and scaffolded format, could reduce the cognitive load some students may experience while trying to navigate and learn from a case study. And finally, we suggest measuring and carefully considering the current level of development of students when selecting tools such as case studies for use in undergraduate courses; matching the timing of certain educational approaches with the current cognitive load capacity of students is likely key to effective learning.

\section{ACKNOWLEDGMENTS}

Publication of this article was funded in part by the Kansas State University Open Access Publishing Fund.

\section{REFERENCES}

Aikens, M. L., \& Dolan, E. L. (2014). Teaching quantitative biology: Goals, assessments, and resources. Molecular Biology of the Cell, 25, 3478-3481.

Albanese, M. (2000). Problem-based learning: Why curricula are likely to show little effect on knowledge and clinical skills. Medical Education, 34, $729-738$.

Allen, D. E., Duch, B. J., \& Groh, S. E. (1996). The power of problem-based learning in teaching introductory science courses. New Directions for Teaching \& Learning, 68, 43-53.

Andrews, T. M., Leonard, M. J., Colgrove, C. A., \& Kalinowski, S. T. (2011) Active learning not associated with student learning in a random sample of college biology courses, CBE-Life Sciences Education, 10, 394-405.

Baeten, M., Struyven, K., \& Dochy, F. (2013). Student-centered teaching methods: Can they optimize students' approaches to learning in professional higher education? Studies in Educational Evaluation, 39, 14-22.

Billings, D. M., \& Halstead, J. A. (2005). Teaching in nursing: A guide for faculty. St. Louis, MO: Saunders.

Bonney, K. M. (2015). Case study teaching method improves student performance and perceptions of learning gains. Journal of Microbiology $\& B i-$ ology Education, 16(1), 21-28.

Campbell, D. T., \& Stanley, J. C. (1963). Experimental and quasi-experimental designs for research on teaching. Chicago, IL: Rand McNally College Publishers. 
Chen, X. (2015). STEM attrition among high-performing college students: Scope and potential causes. Journal of Technology and Science Education, 5(1), 41-59.

Cliff, W. H. (2006). Case-based learning of blood oxygen transport. Advances in Physiological Education, 30, 224-229.

Cliff, W. H., \& Wright, A. W. (1996). Directed case study method for teaching human anatomy and physiology. Advances in Physiology Education, 15, 19-28.

Colliver, J. A. (2000). Effectiveness of problem-based learning curricula: Research and theory. Academic Medicine, 75(3), 259-266.

Dochy, F., Segers, M., Van den Bossche, P., \& Gijbels, D. (2003). Effects of problem based learning: A meta-analysis. Learning and Instruction, 13, 533-568.

Ejiwale, J. (2013). Barriers to successful implementation of STEM education. Journal of Education and Learning, 7(2), 63-74.

Fisher, A. J., Mendoza-Denton, R., Patt, C., Young, I., Eppig, A., \& Garrell, R.L. (2019). Structure and belonging: Pathways to success for underrepresented minority and women PhD students in STEM fields. PLOS ONE, 14(1), e0209279. https://doi.org/10.1371/journal.pone.0209279

Freeman, S., Eddy, S. L., McDonough, M., Smith, M. K., Okoroafor, N., Jordt, H., \& Wenderoth, M. P. (2014). Active learning increases student performance in science, engineering, and mathematics. Proceedings of the National Academy of Sciences USA, 111(23), 8410-8415.

Goldhaber, D. D., \& Brewer, D. J. (1998). When should we reward degrees for teachers? Phi Delta Kappan, 80(2), 134-138.

Graham, M. J., Frederick, J., Byars-Winston, A., Hunter, A. B., \& Handelsman, J. (2013). Increasing persistence of college students in STEM. Science, 341(6153), 1455-1456.

Greenwald, R. R., \& Quitadamo, I. J. (2014). A mind of their own: Using inquiry-based teaching to build critical thinking skills and intellectual engagement in an undergraduate neuroanatomy course. Journal of Undergraduate Neuroscience Education, 12(2), A100-A106.

Hake, R. R. (1998a). Interactive engagement methods in introductory physics mechanics courses. American Journal of Physics, 66, 1.

Hake, R. R. (1998b). Interactive-engagement versus traditional methods: A six-thousand-student survey of mechanics test data for introductory physics courses. American Journal of Physics, 66, 64-74.

Halstead, J. A., \& Billings, D. M. (2005). Teaching and learning in online learning communities. In Billings, D. M., \& Halstead, J. A. (Eds.), Teaching in nursing: A guide for faculty (pp. 423-439). St. Louis, MO: Elsevier.

Herreid, C. (1998). Sorting potatoes for Miss Bonner: Bringing order to casestudy methodology through a classification scheme. Journal of College Science Teaching, 27(4), 236-240.

Herreid, C. (2004). Can case studies be used to teach critical thinking? Journal of College Science Teaching, 33(6), 12-15.

Herreid, C. (2006). The case study method in the STEM classroom. STEM Innovation and Dissemination, 17(4). Retrieved March 13, 2020, from https://journals.iupui.edu/index.php/muj/issue/view/1127

Herreid, C.F., \& Schiller, N. A. (2013). Case studies and the flipped classroom. Journal of College Science Teaching, 42(5), 62-66.

Herreid, C. F., Schiller, N. A., \& Herreid, K. F. (2012). Science stories: Using case studies to teach critical thinking. Arlington, VA: NSTA Press.

Hoag, K. A., Lillie, J. K., \& Hoppe, R. (2005). Piloting case-based instruction in a didactic clinical immunology course. Clinical Laboratory Science, 18(4), $213-220$.

Ingersoll, R., \& Perda, D. (2010). Is the supply of mathematics and science teachers sufficient? American Educational Research Journal, 47(3), 146.

Jozefowicz, R. F. (1994). Neurophobia: The fear of neurology among medical students. Archives of Neurology, 51(4), 328-329.

Kaddoura, M. A. (2011). Critical thinking skills of nursing students in lecture-based teaching and case-based learning. International Journal for the Scholarship of Teaching and Learning, 5(2). https://doi.org/10.20429/ ijsotl.2011.050220

Kaur, S., Kular, P. S., \& Bassi, R. (2019). Case based learning in cardiovascular physiology for first year medical students. Journal of Evolution of Medical and Dental Sciences, 8(13), 1064-1070.

Kennedy, T. J., \& Odell, M. R. L. (2014). Engaging students in STEM education. Science Education International, 25(3), 246-258.
Knight, J. D., Fulop, R. M., Márquez-Magaña, L., \& Tanner, K. D. (2008) Investigative cases and student outcomes in an upper-division cell and molecular biology laboratory course at a minority-serving institution CBE-Life Sciences Education, 7(4), 382-393.

Kulak, V., \& Newton, G. (2014). A guide to using case-based learning in biochemistry education. Biochemistry and Molecular Biology Education, 42(6), 457-473. https://doi.org/10.1002/bmb.20823

Lundeberg, M. A. (2008). Case pedagogy in undergraduate STEM: Research we have, research we need (White paper). Washington, DC: Board of Science Education. Retrieved March 15, 2020, from https://sites nationalacademies.org/cs/groups/dbassesite/documents/webpage/ dbasse_072622.pdf

Maltese, A. V., \& Tai, R. H. (2010). Pipeline persistence: Examining the association of educational experiences with earned degrees in STEM among U.S. students. Science Education, 95(5), 877-907.

Marsh, H. W., Hau, K. T., Artelt, C., Baumert, J., \& Peschar, J. L. (2006). OECD's brief self-report measure of educational psychology's most useful affective constructs: Cross-cultural, psychometric comparisons across 25 countries. International Journal of Testing, 6(4), 311-360.

Mayer, R. E., \& Moreno, R. (2003). Nine ways to reduce cognitive load in multimedia learning. Educational Psychologist, 38(1), 43-52.

McLean, S. F. (2016). Case-based learning and its application in medical and health-care fields: A review of worldwide literature. Journal of Medical Education and Curricular Development, 27(3), 39-49.

McParland, M., Noble, L., \& Livingston, G. (2004). The effectiveness of problem-based learning compared to traditional teaching in undergraduate psychiatry. Medical Education, 38, 859-867.

McRae, M. P. (2012). Using clinical case studies to teach biochemistry in a doctoral program: A descriptive paper. Creative Educaiton, 3(7), 1173-1176.

Michael, J., Cliff, W., McFarland, J., Modell, H., \& Wright, A. (2017). The core concepts of physiology. New York, NY: Springer Science.

Nair, S. P., Shah, T., Seth, S., Pandit, N., \& Shah, G. V. (2013). Case based learning: A method for better understanding of biochemistry in medical students. Journal of Clinical and Diagnostic Research, 7(8), $1576-1578$

Paas, F., Renkl, A., \& Sweller, J. (2003a). Cognitive load theory and instructional design: Recent developments. Educational Psychologist, 38(1), 1-4.

Paas, F., Renkl, A., \& Sweller, J. (2004). Cognitive load theory: Instructional implications of the interaction between information structures and cognitive architecture. Instructional Science, 32, 1-8.

Paas, F., Tuovinen, J. E., Tabbers, H., \& Van Gerven, P. W. (2003b). Cognitive load measurement as a means to advance cognitive load theory. Educational Psychologist, 38(1), 63-71.

Popil, I. (2011). Promotion of critical thinking by using case studies as teaching method. Nurse Education Today, 31, 204-207.

President's Council of Advisors on Science and Technology. (2012). Engage to excel: Producing one million additional college graduates with degrees in science, technology, engineering, and mathematics. Washington, DC: U.S. Government Office of Science and Technology.

Rhodes, A. E., \& Rozell, T. G. (2017). Cognitive flexibility and undergraduate physiology students: Increasing advanced knowledge acquisition within an ill-structured domain. Advances in Physiological Education, 41, 375-382.

Savery, J. R. (2015). Overview of problem-based learning: Definitions and distinctions. In Walker, A. E., Leary, H., Hmelo-Silver, C., \& Ertmer, P. (Eds.), Essential readings in problem-based learning (pp. 5-15). West Lafayette, IN: Purdue University Press.

Seymour, E., \& Hewitt, N. M. (1997). Talking about leaving: Why undergraduates leave the sciences. Boulder, $\mathrm{CO}$ : Westview.

Scott, B. A. N., Mcnair, D. E., Lucas, J. C., \& Land, K. M. (2017). From gatekeeper to gateway. Journal of College Science Teaching, 46(4), 93-99.

Stains, M., Harshman, J., \& Barker, M. K. (2018). Anatomy of STEM teaching in American universities: A snapshot from a large-scale observation study. Science, 359(6383), 1468-1470.

Strenta, A. C., Elliot, R., Adair, R., Matier, M., \& Scott, J. (1994). Choosing and leaving science in highly selective institutions. Research in Higher Education, 35(5), 513-547.

Sweller, J., Ayres, P., \& Kalyuga, S. (2011). Cognitive load theory. New York, NY: Springer Science. 
Tavakol, M., \& Dennick, R. (2011). Post-examination analysis of objective tests. Medical Teacher, 33(6), 447-458.

Terry, D. R. (2007). Using the case study teaching method to promote college students' critical thinking skills (Doctoral dissertation, State University of New York at Buffalo). Retrieved from ProQuest Dissertations Publishing (Publication No. 3277766)

Thistlethwaite, J. E., Davies, D., Ekeocha, S., Kidd, J. M., Macdougall, C., Matthews, P., ... Clay, D. (2012). The effectiveness of case-based learning in health professional education. A BEME systematic review: BEME Guide No. 23. Medical Teacher, 34, 421-444.

Villanueva, M. G., \& Hand, B. (2011). Science for all: Engaging students with special needs in and about science. Learning Disabilities, 26(4), 233-240.

Vilorio, D. (2014). STEM 101: Introduction to tomorrow's jobs (Occupational Outlook Quarterly). Retrieved March 23, 2020, from https://www.bls .gov/careeroutlook/2014/spring/art01.pdf
Wilke, R. R. (2003). The effect of active learning on student characteristics in a human physiology course for nonmajors. Advances in Physiology Education, 27(4), 207-223.

Wilson, A., Rhodes, A., \& Rozell, T. (2017). From twiggy to tubby: The progression of insulin resistance and type // diabetes. National Center for Case Study Teaching in Science. Retrieved May 8, 2020, from https:// sciencecases.lib.buffalo.edu/collection/detail.html?case_id=917\&id=917

Wood, W. (2009). Innovations in teaching undergraduate biology and why we need them. Annual Review of Cell Development and Biology, 25, 93-112.

Yadav, A., Lundeberg, M., DeSchryver, M., \& Dirkin, K. (2007). Teaching science with case studies: A national survey of faculty perceptions of the benefits and challenges of using cases. Journal of College Science Teaching, 37(1), 34-39.

Young, J. Q., van Merrienboer, J., Durning, S., \& Ten Cate, O. (2014). Cognitive load theory: Implications for medical education: AMEE guide no. 86 Medical Teacher, 36(5), 371-384. 